\title{
A storm over steroids
}

Until last year, few people — apart from scientific specialists and those associated with top-level sport - had heard of nandrolone. But in the runup to the Sydney games, this anabolic steroid has repeatedly hit the headlines following the revelation that some of track and field's biggest names have tested positive for the drug — among them Linford Christie, 100-metres sprint champion at the 1992 Barcelona Olympics (pictured).

The resulting controversy has seen the accused athletes and their lawyers question the work of the antidoping scientists and has set

Britain's athletics federation against its international parent body. It has also drawn attention to the nutritional supplements consumed by top athletes, some of which

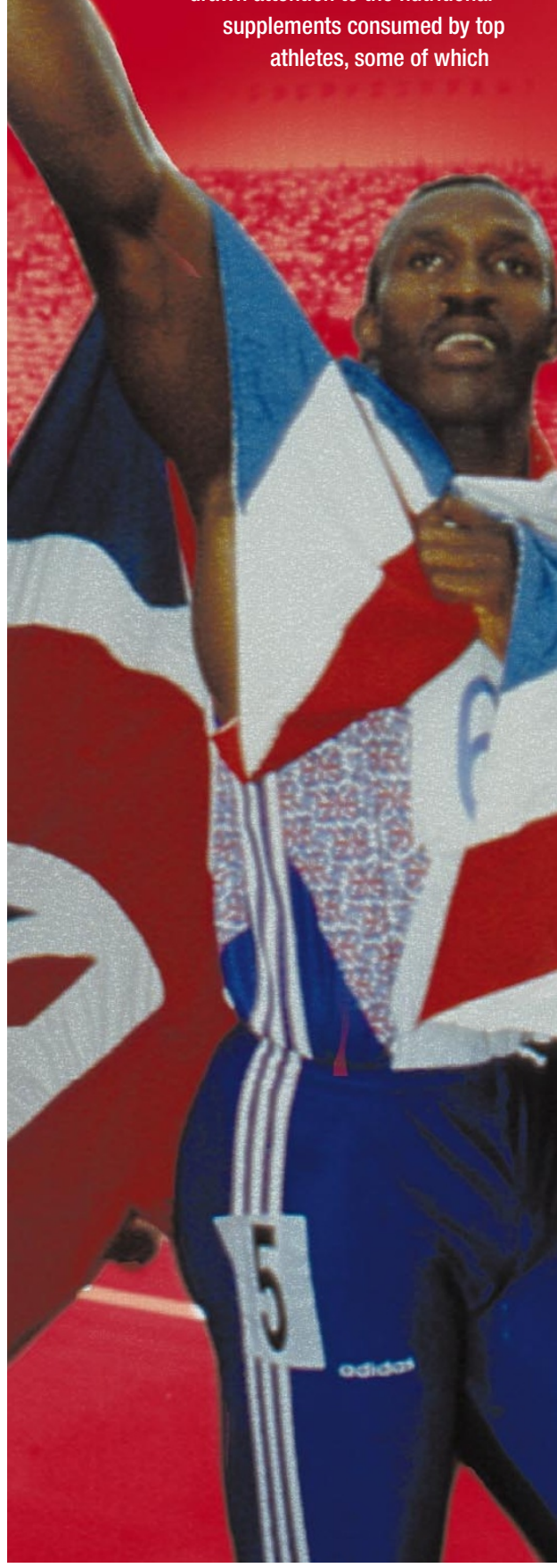

contain traces of nandrolone - even though it is not mentioned on the labelling.

Nandrolone is just one of many synthetic anabolic steroids used in medicine. But they can also be used by athletes, and nandrolone has long been on the International Olympic Committee's list of banned substances. The test used to identify the cheats uses mass spectrometry to detect the main metabolite of nandrolone, 19norandrosterone, in athletes' urine.

Human urine can contain tiny quantities of naturally produced 19-norandrosterone. So the IOC-accredited scientists who devised the nandrolone test conducted validation studies to determine threshold levels of the compound above which an individual can reliably be assumed to have taken the drug or one of its precursors. These have been set at 2 nanograms per millilitre for men, and $5 \mathrm{ng} \mathrm{ml}^{-1}$ for non-pregnant women. The current controversy centres on the validity of these thresholds, with accused athletes - and UK Athletics, which took over as the sport's governing body in Britain after the British Athletics Federation went bankrupt - arguing that individuals could record results above the thresholds without taking any banned substance.

\section{S25:-7: Some athletes have appealed} successfully against positive nandrolone of 3 tests. In July, the Jamaican sprinter 2. 5.5 Merlene 0 ttey was cleared by an 2. International Amateur Athletic Federation (IAAF) arbitration panel after questions were raised about the way her positive test was done. In particular, it emerged that Ottey was dehydrated when she gave her sample - which would have elevated the concentration of 19-norandrosterone in her urine - and this had not been taken into account.

Appeals that seek to undermine the basis for the thresholds are much more ambitious. But that is what Christie and two other British athletes, European 200-metres champion Dougie Walker and 400metres hurdler Gary Cadogan, tried to do last month, when their cases were heard by an IAAF arbitration panel. All three had tested above the threshold for 19-norandrosterone: Cadogan at $10.6 \mathrm{ng} \mathrm{ml}^{-1}$; Walker at $12.6 \mathrm{ng} \mathrm{ml}^{-1}$; and Christie at $200 \mathrm{ng} \mathrm{ml}^{-1}$. With the backing of UK Athletics, which had cleared them of nandrolone abuse, the athletes' arguments rested on unpublished research conducted by Ron Maughan, a physiologist at the University of Aberdeen and a nutritionist for the British Olympic team.

In a project commissioned by UK Athletics and the IAAF, Maughan studied several athletes who had tested positive for nandrolone and a group of physically active, healthy volunteers. The subjects were not monitored continuously, and Maughan does not place too much emphasis on the results from the athletes - who may have had a vested interest in the study's results. More important, he says, are the findings from the healthy volunteers who consumed large quantities of the sort of food supplements used by athletes. First, Maughan tested three volunteers and found that the one who had exercised that day tested above the threshold for the nandrolone tests. In a follow-up study, in which ten volunteers were given supplements and told to exercise, five tested above the threshold.

Maughan stresses that his results are preliminary. "This is at a very early stage and we recognize we need more information," he says. Given this, and questions surrounding the precise methods used, the IAAF panel rejected the British athletes' appeal. Wilhelm Schänzer, director of the IOC-accredited doping control lab in Cologne, which conducted Christie's positive test, argues that the nandrolone test threshold has been subject to extensive validation. "We have data from hundreds of thousands of samples," he says. These data have not been published, but Schänzer adds that a French study on 30 healthy men ${ }^{5}$ found a maximum urinary concentration of 19norandrosterone of $0.32 \mathrm{ng} \mathrm{ml}^{-1}$.

Some positive nandrolone tests could be the result of athletes buying contaminated nutritional supplements. Maughan could find no trace of nandrolone or related compounds in the supplements his volunteers consumed. But several antidoping laboratories, including Schänzer's, have analysed such supplements, procured from athletes or from suppliers advertising on the Internet, and found traces of nandrolone or its precursors not mentioned on the labelling. "We informed the $10 \mathrm{C}$ and the doping control officials of the different sports federations, but so far only the international cycling federation has responded by formally advising its members against using nutritional supplements," says Schänzer.

Although it might seem harsh to take sanctions against those who may have inadvertently consumed a banned substance, the rules state that it is the responsibility of athletes to ensure that they remain clean. The antidoping scientists' job, says Schänzer, "is to say whether or not certain substances are in the body, not how they might have come to get there". 